\title{
First record of Leishmaniasis in wild Jaguars (Panthera onca) from Mexico
}

\author{
Heliot Zarza \\ Departamento de Ciencias Ambientales, CBS, Universidad Autónoma Metropolitana Unidad Lerma, Hidalgo Pte. 46, La \\ Estación, 52006, Lerma de Villada, México.h.zarza@correo.ler.uam.mx \\ Andrés Arias-Alzate \\ Laboratorio de Análisis Espaciales, Instituto de Biología, Universidad Nacional Autónoma de México, Ciudad \\ Universitaria, 04510, México, D.F. México. \& Grupo de Mastozoología Universidad de Antioquia, Medellín, Colombia. \\ José F. González-Maya \\ Instituto de Ecología, Universidad Nacional Autónoma de México, Ciudad Universitaria, 04510, México, D.F. México. \& \\ ProCAT Colombia, Bogotá, Colombia. \\ Cuauhtémoc Chávez
}

Departamento de Ciencias Ambientales, CBS, Universidad Autónoma Metropolitana Unidad Lerma, Hidalgo Pte. 46, La Estación, 52006, Lerma de Villada, México.

Gerardo Ceballos

Instituto de Ecología, Universidad Nacional Autónoma de México, Ciudad Universitaria, 04510, México, D.F. México.

Leishmaniasis is a vector-borne disease and parasitic zoonosis that occurs worldwide (i.e., Latin America, Africa and Eurasian countries; Desjeux 2005, Dahroug et al. 2010, 2011, Otranto et al. 2013). It is caused by parasitic kinetoplastids of the Leishmania genus transmitted by arthropod vectors (i.e. sandflies such as Lutzomyia spp.) and presents a great diversity of clinical profiles, depending on the affected areas (Otranto et al. 2013). This disease mainly affects humans and wild carnivoran species, mostly canids, with dogs as major reservoir hosts (Deane \& Deane 1954, Silva et al. 2000, Figueiredo et al. 2008, Dantas-Torres et al. 2012). Even though domestic and wild felids are unusual reservoirs, and rarely develop the disease, several studies suggest that these species may play an important role in the epidemiology of the disease (Poli et al. 2002, Maia et al. 2008, Nasereddin et al. 2008, Dantas-Torres et al. 2012). Here we report the first record of a clinical manifestation of Leishmaniasis disease in a wild Jaguar (Panthera onca) in Quintana Roo, Mexico.

The case was recorded in March 29, 2002 on a wild male Jaguar, between 10 and 12 years-old, captured in the tropical deciduous forest of Southern Yucatan Peninsula. This capture is part of a long-term Jaguar conservation project carried since 1998 to date in Southern Campeche and Quintana Roo states (18 $15^{\prime} 15^{\prime \prime}$ N, 89 $56^{\prime} 47^{\prime \prime}$ W). After physical examination the Jaguar exhibited a poor health condition; the right eye was diagnosed with cataracts, more than 100 ectoparasites were removed (Dermatobia hominis and ticks (Ixodidae)), and showed a complex cutaneous anomaly in the face. The individual was also diagnosed with pigmented fangs and receding gums, indicating and advanced age of the individual. According to the diagnosis, the jaguar had a large ulcerative lesion on the lips and mouth, with granulated tissue, which was associated with a leishmaniasis lesion and not as a product of previous fight injuries or others causes (Figure 1). It is important to note that only 3 from 34 jaguars captured so far have shown similar injuries.

Cutaneous leishmaniasis can affect cartilaginous tissue and internal structures, including striated muscle and eventually bone, causing severe destruction of these tissues (Desjeux 2005), as detected in this individual. To our knowledge, this is the first report of a clinical manifestation of leishmaniasis in a wild Jaguar in the Americas. Records of wild canids acting as reservoirs have been published for species such as the Hoary fox (Lycalopex vetulus, Deane \& Deane 1954, Courtenary et al. 1996), the Crab-Eating fox (Cerdocyon thous, Silva et al. 2000), and the Bush Dog (Speothos venaticus, Figueiredo et al. 2007), but for felids there are only occurrence records in domestic cats (Poli et al. 2002, Maia et al. 2008, Nasereddin et al. 2008) and no prior cases had been documented in wild felids such as Jaguars. Nevertheless, Dahroug et al. $(2010,2011)$ determine the presence of Leishmania chagasi in captive individuals of Puma concolor, Panthera onca and Panthera leo at the zoological park of the Federal University of Mato Grosso, suggesting that felines, both domestic and wild, can act as reservoirs of $L$. chagasi in endemic areas. Although at the current time no other reports of wild felids exist with the disease, or acting as

\footnotetext{
Mammalogy Notes | Notas Mastozoológicas

Sociedad Colombiana de Mastozoología

Vol. 2 Num. 1| 2015
} 
reservoirs, the impact of leishmaniasis over wild felids remains uncertain, as well as the roll in the epidemiological chain of domestic cats that interact with wildlife in areas where the disease is present. Further studies are needed in order to understand the incidence and prevalence of Leishmania spp. in wild felids and other carnivoran species and its implications in the peridomestic and domestic cycles and its interaction with natural ecosystems.

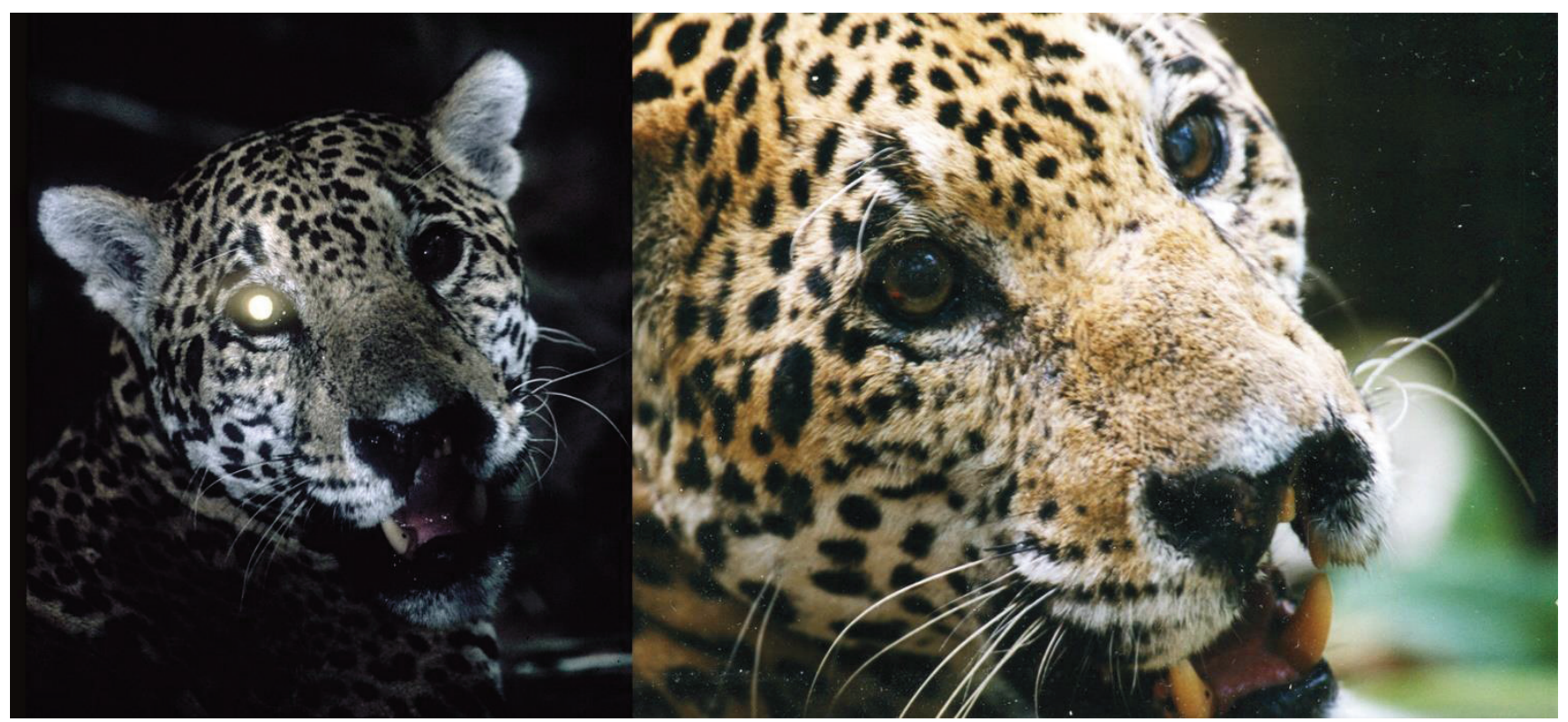

Figure 1. Wild Jaguar (Panthera onca) captured in Quintana Roo, Mexico displaying a clinical manifestation of Leishmaniasis.

\section{Acknowledgements}

We thank Tracy Hill (Safari Creations) for facilitating one of the Jaguar photos, and Francisco Zavala and Marcela Araiza for participating in the field-work and Luis R. Víquez-R for insightful comments. We also wish to thank the WWF-Telcel alliance and the Universidad Nacional Autónoma de México for financial support for this study and the authorities of the Secretaría del Medio Ambiente y Recursos Naturales (Semarnat, INE, Profepa) and the Ejido Caoba for the facilities provided during the project.

\section{References}

CONVIT, J., et al. 2005. Atypical cutaneous leishmaniasis in Central America: possible interaction between infectious and environmental elements. Transactions of the Royal Society of Tropical Medicine and Hygiene 99: 13-17.

COURTENARY, O., et al. 1996. Visceral leishmaniasis in the hoary zorro Dusicyon vetulus: a case of mistaken identity. Transactions of the Royal Society of Tropical Medicine and Hygiene 90: 498-502.

DANTAS-TORRES, F., et al. 2012. Canine leishmaniosis in the Old and New Worlds: unveiled similarities and differences. Trends in Parasitology 28: 531-538.

DAHROUG, M.A., et al. 2010. Leishmania (Leishmania) chagasi in captive wild felids in Brazil. Transactions of the Royal Society of Tropical Medicine and Hygiene 104: 7374. doi:10.1016/j.trstmh.2009.08.003

DAHROUG, M.A., et al. 2011. The first case report of Leishmania (Leishmania) chagasi in Panthera leo in Brazil. Asian Pacific Journal of Tropical Biomedicine 1: 249-250. doi:10.1016/S2221-1691(11)60036-1

DEANE, L.M. \& M.P. DEANE. 1954. Encontro de leishmanias nas visceras e na pele de uma raposa, em zona endemica de calazar, nos arredores de Sobral, Ceará. O Hospital 45: 419-421

DESJEUX, P. 2005. Leishmaniasis cutanea y mucocutanea. Pp.402-407 in El Control de las enfermedades transferibles. (D.L. Heymann ed.). Decimaoctava edición Organización Panamericana de la Salud. Publicación Científica y Técnica No. 613. Washington D.C.

FIGUEIREDO, F.B., et al. 2008. First report of natural infection of a bush dog (Speothos venaticus) with Leishmania (Leishmania) chagasi in Brazil. Transactions of the Royal Society of Tropical Medicine and Hygiene 102: 200-201.

MAIA, C., et al. 2008. Importance of cats in zoonotic leishmaniasis in Portugal. Vector borne Zoonotic Disease 8(4): 555-559.

NASEREDDIN, A., et al. 2008. Feline leishmaniasis in Jerusalem: serological investigation. Veterinary Parasitology 158: 364-369.

OTRANTO, D., et al. 2013. Prevention of canine Leishmaniosis in a hyper-endemic area using a combination of 10\% imidacloprid/4.5\% flumethrin. PLoS ONE 8(2): 1-8.

POLI, A., et al. 2002. Feline leishmaniosis due to Leishmania infantum in Italy. Veterinary Parasitology 26: 181-191.

SILVA, E.S. et al. 2000. Visceral leishmaniasis in the crab-eating fox (Cerdocyon thous) in south-east Brazil. Vet. Rec. 147: 421-422. 